\title{
Fadas em ação: uma breve análise da narrativa "O corvo", de Ana de Castro Osório
}

\author{
Fairies in action: a brief analisis of the story "O corvo" \\ by Ana de Castro Osório
}

\section{$\underline{\underline{\text { Priscila Clementino Bezerra de Araújo }}}$}

\section{Rita de Cássia Silva Dionísio Santos}

1 Acadêmica do curso de Letras da Universidade Estadual de Montes Claros (UNIMONTES). Bolsista da Iniciação Científica Voluntária - ICV, do projeto de pesquisa Narrações da infância na literatura luso-brasileira de autoria feminina: Ana de Castro Osório e Alexina de Magalhães Pinto, coordenado pela professora Rita de Cássia Silva Dionísio Santos. E-mail: pricbaraujo@gmail.com.

2 Doutora em Literatura. Professora da Universidade Estadual de Montes Claros - UNIMONTES. E-mail: cassiadionisio@hotmail.com. 
RESUMO (RESENHA): OSÓRIO, Ana de Castro. "O Corvo". In: Contos Tradicionais Portugueses para as Crianças. Lisboa: Instituto Piaget, 1997.

PALAVRAS-CHAVE: Ana de Castro Osório; conto tradicional; fada

ABSTRACT (REVIEW): OSÓRIO, Ana de Castro. "O Corvo". In: Contos Tradicionais Portugueses para as Crianças. Lisboa: Instituto Piaget, 1997.

KEYWORDS: Ana de Castro Osório. traditional tale; fairy 
Ana de Castro Osório (Portugal,1872-1935), importante feminista dos anos iniciais do século XX, é também conhecida por ser uma referência para a literatura infantil em Portugal. A escrita de seus livros - os quais reúnem contos tradicionais portugueses - teve início em 1897, construída a partir de narrativas de sua terra de origem, cujo foco era recontar os contos populares que eram transmitidos oralmente às crianças.

O Livro Contos Tradicionais Portugueses para as Crianças (inicialmente publicado em $1897^{3}$ ) traz cinco narrativas de diversas temáticas, mas que constituem, em comum, uma espécie de genealogia das histórias de um povo, de uma época em que eram transmitidas oralmente de geração a geração. Todas trazem implícitas ou explícitas, uma moral, podendo corroborar a afirmação de Cascudo (2000, p.10) de que o "conto popular revela informação histórica, etnográfica, sociológica, jurídica, social. É um documento vivo, denunciando costumes, ideias, mentalidades, decisões e julgamentos.”

O conto "O corvo" fecha a coletânea Contos Tradicionais Portugueses para as Crianças. Conta a história de um gênio do mal que foi transformado em um corvo, que deseja se casar, mas tem o seu anseio reiteradamente frustrado, por causa de sua evidente perversidade. Para acabar de vez com a sua solidão, ele decide que irá casar-se, a qualquer custo, com uma bela princesa - e a noiva escolhida é uma bebê recém-nascida, por quem ele se encanta, e decide por sequestrar a criança no exato instante em que ela seria apresentada à corte.

A história passa a girar em torno da tragédia vivida pela nobre família, que, em meio ao desespero, vê-se sem alterantivas de recuperar o seu bem maior: a princesinha de harmoniosa formosura. Surgem, então, outros personagens importantes para o desenrolar do conflito, como o jovem Florêncio e a Fada Urgélia - esta última a quem será designada tarefa de aconselhar a família do imperador sobre a busca de possibilidade de salvamento da princesa. Após um salto temporal, a narrativa segue tensamente, com personagens já adultos, em direção a se restabelecer a ordem inicial. No conto é possível identificar diferentes temáticas como: egoísmo, ambição, valentia, proteção, destino, violência, vingança, desigualdade social, intrigas, amor, maldade, coragem, felicidade e bondade.

Os seres que habitam o conto "O corvo" podem ser definidos como personagens co-

3 A versão que utilizamos é de 1997, edição comemorativa do centenário de lançamento da obra. 
muns aos contos tradicionais, e cada um possui uma função importante para a narrativa. Do rol das personagens ${ }^{4}$, destacamos a mãe preocupada, que sofre com a situação do rapto da filha. O narrador não deixa possibilidades para se conhecer mais sobre a personagem, assim como detalhes psicológicos, sentimentais ou de personalidade. Há também o pai, comprometido com o bem-estar da família e preocupado com a filha. É determinado, e não mede esforços para encontrar sua menina. Sobre a princesa, personagem raptada no início da narrativa, não há muitas descrições, a não ser que é “a mais formosa do mundo” (OSÓRIO,1997, p.67), e sobre o amor que tinha por seu salvador. Florêncio é o homem a quem Deus teria destinado para salvar a princesa, um rapaz corajoso, cavalheiro e principalmente generoso. Na narrativa ele desempenha o papel de herói, sua atitude é importante para o desfecho do conflito. Outra personagem importante é a Fada Urgélia, protetora da família, que se destina a proteger a pequena princesa da maldade do corvo. Surge na narrativa como representação do universo maravilhoso, como uma fada madrinha, que tem papel fundamental no desenrolar do conflito.

A aflição leva a corte a clamar pelos entes mágicos: lembram-se da Fada Urgélia e clamam por seu nome. A Fada chega, conduzida por uma carruagem puxada por pombas. Em sua imponência - porém, com compaixão - a Fada interroga sobre o motivo da dor que a todos afligia. Após a resposta, ela aconselha ao Imperador sobre providências que deveria tomar para reaver sua filhinha. Interessante ressaltar que, sobre a configuração das fadas nos contos maravilhosos, Medeiros (1997, p.117) descreve que elas são responsáveis por portar a harmonia, como entidades mediadoras da relação entre o humano e o mundo mágico.

"O corvo" é uma história de caráter maravilhoso ${ }^{5}$ e, como os contos populares em geral, aponta para a imortalidade da narrativa oral, a partir da representação de cenas e eventos que nunca morrem, que permanecem em um movimento cíclico de início, desenvolvimento e finalidade, nunca o fim.

4 Surgem, também, na narrativa, um homem morto, um cavalo encantado - aos quais, apesar da importância que têm para a abrangência dos sentidos do conto tradicional, por uma questão de economia, não nos dedicaremos neste texto.

5 Além da metamorfose do gênio em corvo, rito de iniciação, castelo e torre são outros elementos próprios aos contos maravilhosos que também comparecem nesta narrativa. 
Conforme os estudos de Medeiros (1997, p.89), nos contos maravilhosos existem "formulas iniciais" e "formulas finais". Este conto em análise segue o modelo tradicional das narrativas orais, iniciando-se com a expressão típica "Era uma vez". Esse recurso transmite ao leitor uma espécie de sinestesia, situando-o em um tempo e espaço da narrativa ficcional, e o transporta para o mundo do maravilhoso.

Como declara Gotlib (2006, p.18), o "conto tem a possibilidade de ser fluido, móvel, de ser entendido por todos, de se renovar nas suas transmissões, sem se desmanchar." Além disso, outra característica que marca a alusão ao conto maravilhoso é a sua referência aos seus finais "felizes para sempre", e que no conto em análise é descrito como: "Foram muito felizes, tiveram muitos filhos e morreram velhinhos e cheio de bençãos” (OSÓRIO,1997, p.70). Isso pode ser confirmado por Medeiros (1997), segundo o qual:

“...as fórmulas de fim nos contos de Ana de Castro Osório retomam ou recriam os finais das narrativas tradicionais, amplificando-as. Em alguns casos pelo seu carácter de literariedade. sem que percam a característica matriz dos finais felizes.” (MEDEIROS, 1997, p.93).

Para Cascudo (2000.p.10) o que caracteriza um conto popular são os aspectos que o determinam como antigo na memória, como anônimo em sua autoria, além da forma como é divulgado nos repertórios orais e a sua persistência. Dessa forma, essas histórias permanecem vivas na memória do contador, e se perpetuam por meio da boca de cada falante. Representam o registro histórico de um povo, o que era contado entre eles, suas crenças, mitos e ritos.

Na narrativa selecionada, observa-se uma significação que revela referências a temáticas negativas, assim como a morte e o azar. O personagem corvo é marcado por essas características, ressoando seu papel na narrativa como um antagonista. Se trata, portanto, de um elemento importante no conto, para estabelecer a natureza moral da história.

Em se tratando da linguagem dos contos de Ana de Castro Osório, é possível identificar referências a origem da contação, aspectos da oralidade. A maneira como a história é escrita aproxima o leitor, como um ouvinte, e o narrador como sendo um "contador-criador-escritor" (GOTLIB ,2006, p.13). E assim, é definido o caráter literário da autora em análise.

As personagens, lugares, e tempos deste conto são indeterminados, não têm uma pre- 
cisão histórica. Ainda que, nele, os acontecimentos sejam apresentados em ordem cronológica, representando passagem do tempo, as transformações dos personagens e amadurecimento (GOTTLIB, 2006, p.18), trata-se de um tempo mágico, maravilhoso, que não se consegue calcular, em que suas mudanças são ilógicas, se se considerar o plano da realidade. Isso pode ser identificado no excerto em que se conta o tempo entre a idade que o rapaz tinha quando salvou a princesa ainda bebê até o momento em que ele se casa com ela.

A literatura contextualiza experiências que permitam ao leitor reconhecer-se humano, a partir da representação de experiências vividas no plano ficcional. Nessa mirada, Ana de Castro Osório, ao recolher histórias da tradição oral portuguesa e conceder a elas uma forma escrita, colabora para salvá-las do esquecimento. 


\section{Referências}

OSÓRIO, Ana de Castro. Contos Tradicionais Portugueses para as Crianças. Lisboa: Instituto Piaget, 1997.

CASCUDO. Luís da Câmara. Contos tradicionais do Brasil.14ed.Rio de Janeiro:Ediouro,2000.

GOTLIB. Nádia Battella. Teoria do conto. 11.ed.-São Paulo: Ática,2006. 95p.

MEDEIROS. Maria de Fátima da Câmara Ribeiro. Do fruto a raiz, uma introdução às histórias maravilhosas da tradição popular portuguesa recolbidas e recontadas por Ana de Castro Osório. Faculdade de Ciências Sociais e Humanas UNIVERSIDADE NOVA DE LISBOA. Lisboa, 1997. Disponível em: <https://run.unl.pt/handle/10362/30467> Acesso em: 29 de dez. 2019. 